\title{
Bruk av snus og røyketobakk hos gravide i Agder
}

BAKGRUNN Bruk av snus under graviditeten gir økt risiko for dødfødsel, prematur fødsel og redusert fødselsvekt. Det har vært advart mot røyking i svangerskapet, men mindre mot bruk av snus. Vi har undersøkt bruken av snus og røyketobakk hos gravide i Agderfylkene.

MATERIALE OG METODE Data om gravide og 10583 fødsler for årene 2012, 2013 og 2014 ble hentet ut fra elektronisk fødejournal ved Sørlandet sykehus.

RESULTATER I treårsperioden 2012-14 brukte $5 \%$ snus og $19 \%$ røyketobakk før svangerskapet og henholdsvis $2 \%$ og $8 \%$ i slutten av svangerskapet. Bruken av snus før svangerskapet økte fra 3,6 \% i 2012 til 6,8 \% i 2014. Tilsvarende tall for første trimester var $1,7 \%$ og $3,4 \%$, for siste trimester $1,2 \%$ og 2,1 \%. Bruk av røyketobakk ble redusert med $2 \%$ i treårsperioden. I aldersgruppen 16-24 år brukte $12 \%$ snus før svangerskapet og $5 \%$ i slutten. Av 522 kvinner som brukte snus før svangerskapet, hadde $57,5 \%$ sluttet i første trimester og $71,4 \%$ i tredje trimester. Tilsvarende tall for de 2015 kvinnene som brukte røyketobakk før svangerskapet var $45,2 \%$ og $58,0 \%$ ( $p<0,001)$.

FORTOLKNING Bruken av snus før og i svangerskapet ble fordoblet i treårsperioden 2012-14, spesielt blant de yngste. Andelen gravide som sluttet med snus i svangerskapet var signifikant høyere enn andelen som sluttet med røyketobakk.

Snusbruk er spesielt for Norge og Sverige, siden salg av snusprodukter er forbudt i EU. Sverige har fått unntak fra forbudet.

Flere studier fra de senere år gir holdepunkter for at bruk av snus under graviditeten kan ha uheldige virkninger i svangerskapet og på det nyfødte barn $(1,2)$. Spesielt er dette vist i store befolkningsundersøkelser fra det svenske fødselsregisteret. Bruk av snus i graviditeten gir økt risiko for dødfødsel, prematur fødsel og redusert fødselsvekt (3-5) og er også assosiert med svangerskapsforgiftning, leppe-gane-spalte og apné hos nyfødte (6-8).

Siden bruk av snus altså er et fenomen som er nokså spesifikt for Sverige og Norge, finnes det ikke like gode og store studier fra andre land. Funnene er imidlertid delvis bekreftet i noen studier fra land der man bruker andre typer røykfri tobakk, herunder India $(9,10)$ og Sør-Afrika (11).

De siste ti årene er salget av snus tredoblet i Norge, og økningen i bruk har vært særlig stor blant yngre kvinner (1). I 2014 brukte $4 \%$ av norske kvinner snus daglig og $3 \%$ av og til. I aldersgruppen 16-24 år var $18 \%$ av kvinnene snusbrukere og i aldersgruppen 25-34 år $16 \%$ (12). Samtidig med at færre unge begynner å røyke, har det vært en økning i bruken av snus, også i ressurssterke miljøer, som blant studenter, idrettsutøvere og militære (13).

Bruk av snus er en relativt ny trend blant unge kvinner. Dersom de blir avhengige, kan det bli vanskelig å slutte når de blir gravide. Snus blir anbefalt av flere som røykeerstatning i skadereduserende hensikt fordi det gir mindre helseskade enn røyetobakk og fordi snusing er assosiert med redusert røyke- prevalens (14-17). Faren er imidlertid at snus kan få økt utbredelse i grupper der man ellers ikke ville begynt med tobakk (18). Dette kan føre til at flere unge kvinner er snusbrukere når de blir gravide.

Snusbruk er hittil ikke blitt registrert på helsekort for gravide. Dette kan gi et signal om at snus i graviditeten er mindre farlig enn røyketobakk. Det er ukjent i hvilken grad problemområdet blir tatt opp av jordmor og fastlege i svangerskapsomsorgen (19).

Bruk av snus hos gravide er ikke tidligere kartlagt i Norge, bortsett fra i et ikke-representativt utvalg i mor-og-barn-undersøkelsen (1). Det er ukjent i hvilken grad gravide snusbrukere slutter i løpet av svangerskapet. Ved Sørlandet sykehus har man brukt elektronisk fødejournal i flere år og bruk av både snus og røyketobakk blir registrert. Fra 2014 har alle norske fødeavdelinger registrert både sigarettrøyking og snusbruk i elektroniske fødejournaler, men foreløpig er det kun røykevaner som blir rapportert til Medisinsk fødselsregister (20).

I denne studien ønsket vi å undersøke tendenser i bruk av snus og røyketobakk hos kvinner som fødte ved Sørlandet sykehus i årene 2012-14. Siden vi antok at snus blir ansett som mindre farlig enn røyketobakk, var vår hypotese at andelen som sluttet med snus ville være lavere enn andelen som sluttet å røyke i løpet av svangerskapet.

\section{Materiale og metode}

Materialet omfatter anonymiserte data for alle fødsler i årene 2012, 2013 og 2014 på Sørlandet sykehus' tre fødeavdelinger i

\section{Ellen Rygh}

ryghellen@gmail.com

Forskergruppen for primærleger i Agder Arendal

Frode Gallefoss

Forskningsenheten

Sørlandet sykehus, Kristiansand

\section{Harald Reiso}

Helsam, avdeling for allmennmedisin

Universitetet i Oslo

> Se lederartikkel side 1320

Engelsk oversettelse på www.tidsskriftet.no

\section{HOVEDBUDSKAP}

Det var i Agderfylkene fra 2012 til 2014 nesten en dobling av de gravides bruk av snus

Andelen som brukte snus før graviditeten og sluttet med dette i løpet av svangerskapet var høyere enn andelen som sluttet med røyketobakk

Av dem som brukte snus eller som røykte før graviditeten, var det $29 \%$ av snuserne og $42 \%$ av røykerne som fortsatte gjennom svangerskapet 
Tabell 1 Brukere av snus og røyketobakk i svangerskapet. Sammenslåtte data for 2012-14. N = 10583

\begin{tabular}{|c|c|c|c|c|c|c|c|c|c|}
\hline & \multicolumn{4}{|c|}{ Snus } & \multicolumn{5}{|c|}{ Røyketobakk } \\
\hline & Av og til & \multicolumn{2}{|c|}{ Daglig } & $\begin{array}{l}\text { Sum Av og til } \\
\text { + Daglig }\end{array}$ & \multicolumn{2}{|c|}{ Av og til } & \multicolumn{2}{|c|}{ Daglig } & $\begin{array}{l}\text { Sum Av og til } \\
\text { + Daglig }\end{array}$ \\
\hline & Antall (\%) & Antall & $(\%)$ & Antall (\%) & Antall & $(\%)$ & Antall & $(\%)$ & Antall $(\%)$ \\
\hline Før svangerskapet & $174 \quad(1,6)$ & 351 & $(3,3)$ & $525 \quad(4,9)$ & 443 & $(4,2)$ & 1577 & $(14,9)$ & $2020 \quad(19,1)$ \\
\hline 1. trimester & $119 \quad(1,1)$ & 141 & $(1,3)$ & $260 \quad(2,4)$ & 192 & $(1,8)$ & 946 & $(8,9)$ & $1138 \quad(10,7)$ \\
\hline 3. trimester & $86 \quad(0,8)$ & 90 & $(0,9)$ & $176 \quad(1,7)$ & 135 & $(1,3)$ & 705 & $(6,7)$ & $840 \quad(8,0)$ \\
\hline
\end{tabular}

Flekkefjord, Kristiansand og Arendal, i alt 10583 fødsler.

Opplysninger om kvinnenes bruk av snus og røyketobakk før og under svangerskapet, deres utdanningsnivå og barnas fødselsvekt og apgarskår ble hentet ut fra den elektroniske fødejournalen Partus. I journalen er bruk av snus og røyketobakk registrert som daglig og av og til, henholdsvis før graviditeten, i svangerskapets første trimester (registret ved 18-ukerskontrollen) og i svangerskapets tredje trimester (registrert ved innskrivningssamtalen på fødeavdelingen).

Datauttrekket ble foretatt av Sykehuspartner og overført til SPSS, versjon 21, hvor beskrivende statistikk ble anvendt. Andelen brukere som sluttet i svangerskapet med henholdsvis snus og røyketobakk ble beregnet fra før svangerskapet til første trimester og fra før svangerskapet til tredje trimester. Signifikansverdier for forskjellene ble beregnet med toutvalgstest mellom andelene.

$2012 \square 2013 \square 2014$

Brukere av snus*

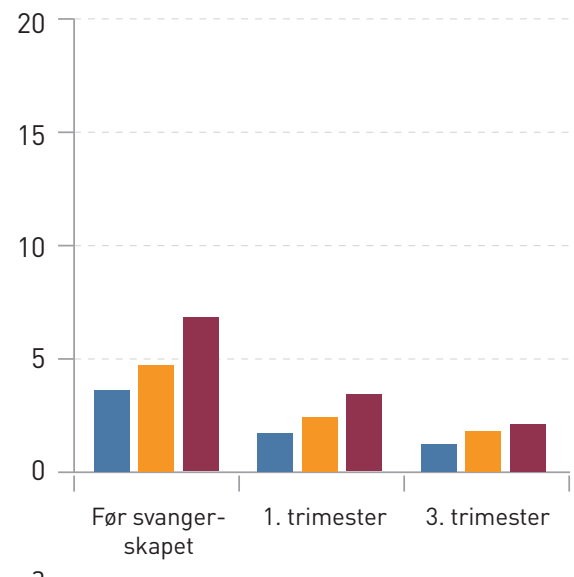

Studien er godkjent av regional etisk komité (2014/654 REK Sør-Øst).

\section{Resultater}

Materialet omfattet 10583 barnefødsler ved Sørlandet sykehus. Bruk/ikke-bruk av snus var registrert i fødejournalen hos $98,8 \%$ av kvinnene før svangerskapet, hos 96,9\% i første trimester og hos $95,9 \%$ i tredje trimester. Tilsvarende svarprosenter for røyketobakk var henholdsvis 98,4\%, 99,4\% og $97,0 \%$. Samlet andel gravide som brukte snus daglig eller av og til var 4,9\% før svangerskapet, $2,4 \%$ i første trimester og $1,7 \%$ i tredje trimester. Andelen som brukte røyketobakk var henholdsvis $19,1 \%, 10,7 \%$ og $8,0 \%$ (tab 1$)$.

\section{Tendens over tid}

Fra 2012 til 2014 var det nær en dobling i bruken av snus før svangerskapet - fra 3,6\% til $6,8 \%$. Tilsvarende tall for første trimester var

\section{Brukere av røyketobakk*}

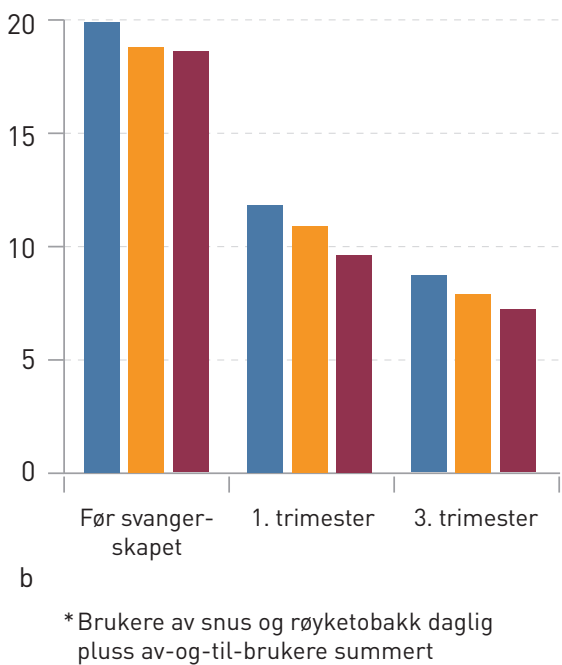

Figur 1 Tidstrend 2012-14. Brukere av snus og røyketobakk i prosent ( $N=10583)$ fra $1,7 \%$ til $3,4 \%$ og for tredje trimester fra $1,2 \%$ til $2,1 \%$. Når det gjaldt røyking, var det en reduksjon fra $19,9 \%$ til $18,6 \%$ før svangerskapet, fra $11,8 \%$ til $9,8 \%$ i første trimester og fra $8,7 \%$ til $7,2 \%$ i siste trimester (fig 1 ).

\section{Aldersgrupper}

Snusbruken var høyest i aldersgruppen 16-24 år, der 12,2\% brukte snus før svangerskapet, den var 7,1 \% i første trimester og $4,6 \%$ i tredje trimester (fig 2). I samme aldersgruppe var andelen røykere henholdsvis $32,7 \%, 22,4 \%$ og $15,4 \%$.

I aldersgruppen 25-34 år brukte 4,1\% snus før svangerskapet, $1,8 \%$ i første trimester og $1,2 \%$ i tredje trimester. Andelen røykere var i denne aldersgruppen henholdsvis $17,1 \%, 8,9 \%$ og $6,7 \%$.

\section{Utdanning}

Det var en stor utdanningsgradient for bruk av røyketobakk, men dette var ikke så tydelig for snus. Blant dem som brukte snus før svangerskapet, var det en liten overvekt som hadde videregående skole som høyeste utdanning.

Det var få med høyskole- eller universitetsutdanning som brukte snus eller røyketobakk under graviditeten, sammenlignet med dem med lavere utdanning (fig 3 ).

\section{Endring i svangerskapet}

Av 522 kvinner som brukte snus før svangerskapet, hadde $300(57,5 \%$; $95 \%$ KI $53-62 \%$ ) sluttet i forste trimester og 364 $(71,4 \%$; $95 \%$ KI $66-74 \%)$ i tredje trimester. Av 2015 kvinner som brukte røyketobakk før graviditeten, hadde 910 (45,2\%; $95 \%$ KI $43-47 \%$ ) sluttet i første trimester og $1141(58,0 \%$; $95 \%$ KI 54-59\%) i tredje trimester.

Andelen gravide som sluttet å bruke snus i svangerskapet var signifikant høyere enn andelen som sluttet å røyke $(\mathrm{p}<0,001)$. $42,4 \%$ av dem som snuste før svangerskapet og $54,8 \%$ av dem som røykte, fortsatte i første trimester, og henholdsvis $28,6 \%$ og $42,0 \%$ fortsatte i siste trimester. 


\section{Fødselsvekt og apgarskår}

Gjennomsnittlig fødselsvekt for barn av mødre som hadde røykt daglig eller av og til i siste trimester, var $3331 \mathrm{~g}$, mot $3533 \mathrm{~g}$ i ikke-røykergruppen. Den gjennomsnittlige reduksjonen i fødselsvekt på 202 g var statistisk signifikant $(\mathrm{p}<0,001)$.

Det ble ikke funnet noen signifikant forskjell i fødselsvekt mellom barn av mødre som hadde brukt snus og barna til dem som ikke hadde brukt snus. Det ble heller ikke funnet noen forskjell i apgarskår der mor hadde brukt snus eller røyketobakk i siste trimester, sammenliknet med ikke-brukerne.

\section{Diskusjon}

Det var en nær dobling i de gravides bruk av snus i Agderfylkene fra 2012 til 2014. En signifikant høyere andel brukere av snus enn av røyketobakk sluttet i løpet av svangerskapet. Dette kan tyde på at det synes å være lettere å slutte med snus enn å slutte å røyke.

\section{Samsvar med andre undersøkelser}

Agderfylkene har ligget under landsgjennomsnittet $i$ bruk av snus og over gjennomsnittet i bruk av røyketobakk (12). Også i vår populasjon, gravide kvinner i Agderfylkene 2012-14, var snusbruken før svangerskapet lavere enn landsgjennomsnittet, 5\% mot $7 \%$ i landet. I 2014 var imidlertid bruken av snus før svangerskapet økt til $7 \%$, som tilsvarer landsgjennomsnittet.

Andelen røykere blant de gravide kvinnene i Agder var høyere enn landsgjennomsnittet, $11 \%$ mot $7 \%$ i landet ved svangerskapets begynnelse og $8 \%$ mot $4 \%$ ved svangerskapets slutt (20). Andelen gravide som brukte snus i vår undersøkelse var tilnærmet lik den i Sverige. Ifølge tall fra det svenske fødselsregisteret var andelen som brukte snus før svangerskapet i 2012 3,5\%, mot 3,6\% i Agderfylkene, og henholdsvis $1,2 \%$ mot $1,7 \%$ i første trimester og $0,7 \%$ mot $1,2 \%$ i siste trimester (21). Dette tyder på at problemets omfang kan være like stort som det er i Sverige.

Vi fant en statistisk signifikant reduksjon i barns fødselsvekt der kvinner hadde brukt røyketobakk i slutten av svangerskapet, men ingen forskjell ved bruk av snus, sammenliknet med ikke-brukere. Disse tallene er ikke korrigert for sosioøkonomiske faktorer. Effekten av snus på fosterets vekst er ikke like godt studert som effekten av røyketobakk.

En større studie fra det svenske fødselsregisteret viste at risikoen for at barnet skulle være lite for alderen ved fødselen (small for gestational age) var lavere ved snusbruk enn ved tobakksrøyking tidlig i svangerskapet (justert OR 1,26; $95 \%$ KI 1,09-1,46, mot 2,55; $95 \%$ KI 2,43-2,67) (5). Også andre studier tyder på at bruk av snus ikke påvirker fosterets vekst like mye som røyking (11,

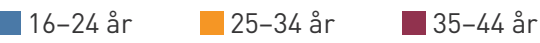

Brukere av snus*

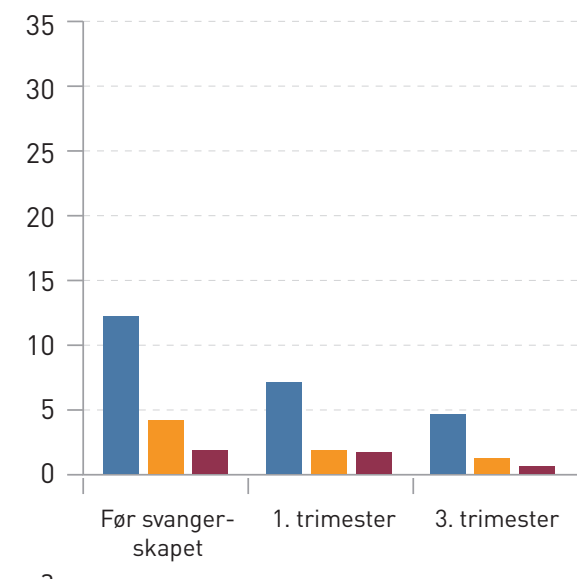

Figur 2 Brukere av snus og røyketobakk i årene 2012-14 etter aldersgrupper i prosent ( $N=10$ 583)

22). Det diskuteres om dette kan ha med toksiske forbrenningsprodukter å gjøre, som for eksempel kullosnivå i blodet hos røykere, i tillegg til eventuelle nikotinvirkninger (23).

\section{Validitet}

Styrken i denne studien er at den undersøkte populasjonen er stor og at det er høye svarprosenter (mellom 96 og 99). En svakhet i undersøkelsen er mulig underrapportering. Svarprosentene var lavest i siste trimester, og lavere for snus enn for røyketobakk.

\section{Grunnskole Videregående skole}

Brukere av snus*

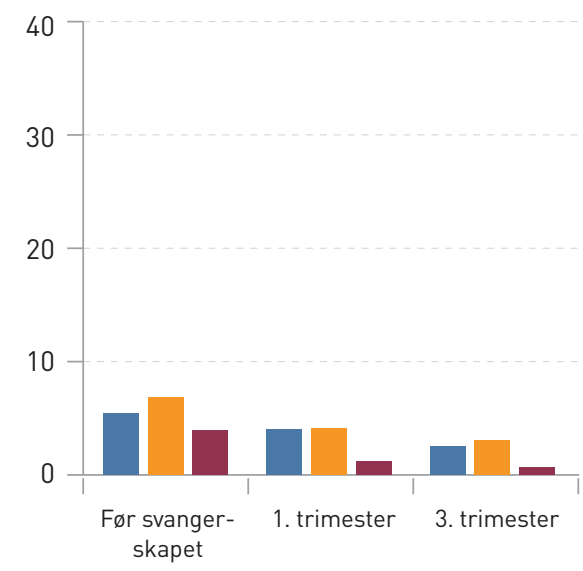

a
Dersom det var registrert i Partus ved tidligere konsultasjoner at kvinnen ikke brukte snus eller røyetobakk, kan jordmor ha funnet spørsmålet uaktuelt og unnlatt å stille det, noe som kan ha bidratt til underrapportering. Vi må videre anta at spørsmål om tobakksbruk kan oppleves som tabubelagte og vanskelige for den gravide å svare ærlig på, noe som kan bidra til manglende eller unøyaktige opplysninger. Dette understrekes ved forskrift om at registering av snusbruk og røykevaner skal være frivillig og at det skal gis skriftlig infor-

Figur 3 Brukere av snus og røyketobakk i årene 2012-14 etter høyeste utdanningsnivå i prosent ( $N=10$ 583)

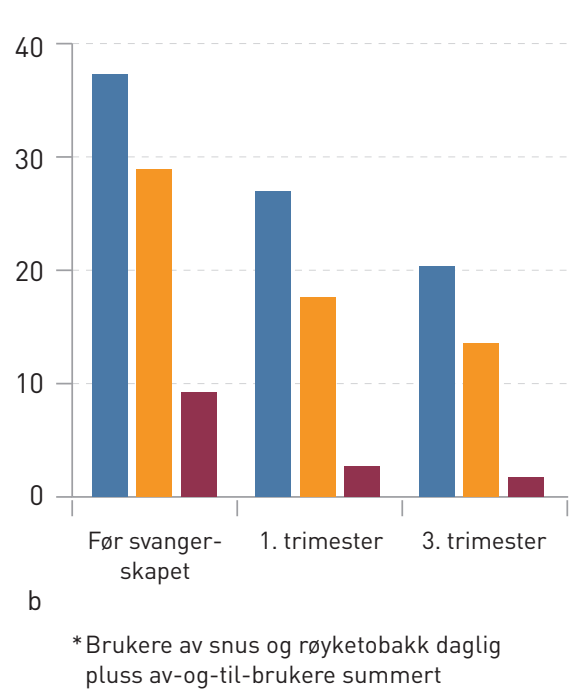


masjon om formålet med rapporteringen til Medisinsk fødselsregister (20).

\section{Livsstilsråd og forebygging}

Snusbruk er relativt nytt hos unge kvinner. Tidsgradienten og aldersgradienten tilsier at om noen år kan mange flere kvinner være snusbrukere når de blir gravide. Vår undersøkelse tyder på at $42 \%$ av dem som brukte snus før svangerskapet, fortsatte i første trimester, og $29 \%$ i tredje trimester.

En porsjon snus gir et noe høyere nikotinopptak i blodet enn en sigarett og nikotinen holder seg der lenger (1). Nikotin passerer placentabarrieren raskt, og konsentrasjonen er $15 \%$ høyere i fosterets plasma enn i morens (24). Siden man ikke kjenner nedre grenser for skadevirkninger på fosteret, er dette et potensielt folkehelseproblem.

Helsekortet for gravide er revidert, og nå skal bruk av snus også registreres. Dette vil tilsi at skadevirkninger ved bruk av snus $i$ større grad blir en del av rådgivningen til gravide fra første svangerskapskontroll, på lik linje med advarsler mot bruk av røyketobakk.

Andelen røykere i vår undersøkelse var spesielt høy i aldersgruppen 16-24 år, der $22 \%$ røykte i første trimester og $15 \%$ i tredje trimester. Dette tilsier at røyking fortsatt er det største tobakksrelaterte problemet i svangerskapet, spesielt gjelder det de yngste.

Vi fant en stor utdanningsgradient når det gjaldt bruk av røyketobakk, men ikke så utpreget for snus. Dette samsvarer med at det $i$ de senere år har vært en minkende forskjell i snusbruk mellom utdanningsgrupper, i motsetning til tidligere, da bruk av snus var vanligst $i$ grupper med høyere utdanning (1). Dette tyder på at økningen i snusbruk nå har nådd yngre aldersgrupper og dem med lavest utdanning. I vår undersøkelse var utbredelsen av snus nærmest lik hos dem med grunnskole og dem med videregående som høyeste utdanning i første trimester (4\%) og i tredje trimester $(3 \%)$, men bare ca. $1 \%$ av dem med høyere utdanning brukte snus i løpet av svangerskapet.

Dette har betydning for hvordan forebyggende tiltak bør innrettes: Rådgivning om skadevirkninger ved bruk av snus bør settes inn så tidlig som mulig hos unge jenter, for eksempel $\mathrm{i}$ forbindelse med prevensjonskonsultasjoner.

\section{Konklusjon}

Det var en nær dobling i de gravides bruk av snus fra 2012 til 2014. Signifikant flere kvinner sluttet med snus enn med røyketobakk i løpet av svangerskapet. Undersøkelsen bekrefter at bruk av snus er økende blant gravide i Agderfylkene og kan representere et potensielt folkehelseproblem dersom tendensen vedvarer.

Vi takker Forskergruppen for primærleger i Agder for kollegastøttet veiledning.

Førsteforfatter har mottatt stipend fra Legeforeningens allmennmedisinske forskningsutvalg.

\section{Ellen Rygh (f. 1946)}

er spesialist i samfunnsmedisin og tidligere spesialist i allmennmedisin. Hun har vært fylkeslege, kommunelege og sykehuslege, men er nå pensjonist. Hun har siden starten i 1994 vært aktiv i Forskergruppen for primærleger i Agder Forfatter har fylt ut ICMJE-skjemaet og oppgir ingen interessekonflikter.

\section{Frode Gallefoss (f. 1956)}

er dr.med., spesialist i indremedisin og i lungesykdommer, forskningssjef ved Sørlandet sykehus og tidligere seksjonsoverlege ved Lungeseksjonen, Sørlandet sykehus Kristiansand. Han er professor II ved Klinisk institutt 2, Universitetet i Bergen.

Forfatter har fylt ut ICMJE-skjemaet og oppgir ingen interessekonflikter.

\section{Harald Reiso (f. 1955)}

er dr.med. og spesialist i allmennmedisin og i samfunnsmedisin. Han er fastlege ved Tromøy legesenter, rådgiver ved Flåttsenteret ved Sørlandet sykehus og forsker ved Helsam. Han har vært med i Forskergruppen for primærleger i Agder siden starten i 1994

Forfatter har fylt ut ICMJE-skjemaet og oppgir ingen interessekonflikter.

\section{Litteratur}

1. Helserisiko ved bruk av snus. Oslo: Nasjonalt folkehelseinstitutt, 2014. www.fhi.no/publ/2014/ helserisiko-ved-bruk-av-snus/ (1.7.2016).

2. Inamdar AS, Croucher RE, Chokhandre MK et al. Maternal Smokeless Tobacco Use in Pregnancy and Adverse Health Outcomes in Newborns: A Systematic Review. Nicotine Tob Res 2015; 17 1058-66.

3. Baba S, Wikström AK, Stephansson 0 et al. Influence of snuff and smoking habits in early pregnancy on risks for stillbirth and early neonatal mortality. Nicotine Tob Res 2014; 16: 78-83.

4. Baba S, Wikström AK, Stephansson 0 et al. Influence of smoking and snuff cessation on risk of preterm birth. Eur J Epidemiol 2012; 27: 297-304. 5. Baba S, Wikström AK, Stephansson 0 et al. Chan- ges in snuff and smoking habits in Swedish pregnant women and risk for small for gestational age births. BJOG 2013: 120: 456-62.

6. Wikström AK, Stephansson O, Cnattingius S. Tobacco use during pregnancy and preeclampsia risk: effects of cigarette smoking and snuff. Hypertension 2010: 55: 1254-9.

7. Gunnerbeck A, Edstedt Bonamy AK, Wikström AK et al. Maternal snuff use and smoking and the risk of oral cleft malformations-a population-based cohort study. PLoS One 2014; 9: e84715.

8. Gunnerbeck A, Wikström AK, Bonamy AKE et al. Relationship of maternal snuff use and cigarette smoking with neonatal apnea. Pediatrics 2011; 128: 503-9

9. Gupta PC, Subramoney S. Smokeless tobacco use, birth weight, and gestational age: population based, prospective cohort study of 1217 women in Mumbai, India. BMJ 2004; 328: 1538.

10. Gupta PC, Subramoney S. Smokeless tobacco use and risk of stillbirth: a cohort study in Mumbai, India. Epidemiology 2006; 17: 47-51.

11. Steyn $K$, de Wet T, Saloojee $Y$ et al. The influence of maternal cigarette smoking, snuff use and passive smoking on pregnancy outcomes: the Birth To Ten Study Paediatr Perinat Epidemiol 2006. 20.90-9.

12. Statistisk sentralbyrå. www.ssb.no/royk/ (1.7.2016).

13. Lund KE, Tefre EM, Amundsen A et al. Røyking, bruk av snus og annen risikoatferd blant studenter. Tidsskr Nor Legeforen 2008; 128: 1808-11.

14. Daniel Roth H, Roth AB, Liu X. Health risks of smoking compared to Swedish snus. Inhal Toxicol 2005; 17: 741-8.

15. Scheffels J, Lund KE, McNeill A. Contrasting snus and NRT as methods to quit smoking. an observational study. Harm Reduct J 2012; 9: 10

16. Gartner CE, Hall WD, Vos T et al. Assessment of Swedish snus for tobacco harm reduction: an epidemiological modelling study. Lancet 2007; 369: 2010-4.

17. Lund I, Lund KE. How has the availability of snus influenced cigarette smoking in Norway? Int J Environ Res Public Health 2014: 11: 11705-17.

18. Lambe M. Swedish snus for tobacco harm reduction. Lancet 2007; 370: 1206-7.

19. Universitetet $\mathrm{i}$ Troms $\varnothing$. Nyheter. Snusing kan forårsake dødfødte barn. 8.6.2012. https://uit.no/ nyheter/artikkel?p document id $=306019$. (1.7.2016).

20. Medisinsk fødselsregister. www.fhi.no/hn/ helseregistre-og-biobanker/mfr/medisinskfodselsregister---helsere/ (1.7.2016).

21. Tobaksvanor bland gravida. Medicinska födelseregistret 1973-2012. Artikelnr 2013-12-16. Stockholm: Socialstyrelsen, 2013

22. England LJ, Levine RJ, Mills JL et al. Adverse pregnancy outcomes in snuff users. Am J Obstet Gynecol 2003; 189: 939-43.

23. Juárez SP, Merlo J. The effect of Swedish snuff (snus) on offspring birthweight: a sibling analysis. PLoS One 2013; 8: e65611.

24. Luck W Nau H, Hansen $\mathrm{R}$ et al. Extent of nicotine and cotinine transfer to the human fetus, placenta and amniotic fluid of smoking mothers. Dev Phar macol Ther 1985; 8: 384-95.

Mottatt 14.12. 2015, første revisjon innsendt 1.4 2016, godkjent 9.6. 2016. Redaktør: Lars Frich. 